\title{
Streptococcus anginosus (milleri) Group Strains Isolated in Poland (1996-2012) and their Antibiotic Resistance Patterns
}

\author{
KATARZYNA OBSZAŃSKA ${ }^{1}$, IZABELLA KERN-ZDANOWICZ , ALEKSANDRA KOZIŃSKA², \\ KATARZYNA MACHURA ${ }^{3}$, ELŻBIETA STEFANIUK ${ }^{2,4}$, WALERIA HRYNIEWICZ ${ }^{2,4}$ and IZABELA SITKIEWICZ ${ }^{3 *}$ \\ ${ }^{1}$ Department of Microbial Biochemistry, Institute of Biochemistry and Biophysics, \\ Polish Academy of Sciences, Warsaw, Poland \\ ${ }^{2}$ Department of Epidemiology and Clinical Microbiology, National Medicines Institute, Warsaw, Poland \\ ${ }^{3}$ Department of Molecular Microbiology, National Medicines Institute, Warsaw, Poland \\ ${ }^{4}$ Centre of Quality Control in Microbiology (Polmicro), Warsaw, Poland
}

Submitted 1 December 2015, accepted 21 December 2015

Abstract

\begin{abstract}
Streptococcus anginosus, Streptococcus intermedius and Streptococcus constellatus form a group of related streptococcal species, namely the Streptococcus Anginosus Group (SAG). The group, previously called "milleri” had been rarely described until 1980/1990 as source of infections. Nowadays SAG bacteria are often described as pathogens causing predominantly purulent infections. The number of infections is highly underestimated, as SAG strains are often classified in the microbiology laboratory as less virulent "viridans streptococci". Epidemiological situation regarding SAG infections in Poland has been unrecognized, therefore we performed a retrospective analysis of strains isolated between 1996 and 2012. Strains suspected of belonging to SAG were re-identified using an automated biochemical approach (Vitek2) and MALDI-TOF MS. We performed first analysis of antibiotic resistance among SAG strains isolated in Poland using automated methods (Vitek2), disk diffusion tests and E-Tests. We also performed PCR detection of resistance determinants in antibiotic resistant strains. Clonal structure of analyzed strains was evaluated with PFGE and MLVF methods. All three species are difficult to distinguish using automated diagnostic methods and the same is true for automated MIC evaluation. Our analysis revealed SAG strains are rarely isolated in Poland, predominantly from purulent infections. All isolates are very diverse on the genomic level as estimated by PFGE and MLVF analyses. All analyzed strains are sensitive to penicillin, a substantial group of strains is resistant to macrolides and the majority of strains are resistant to tetracycline.
\end{abstract}

Ke y w or d s: Streptococcus anginosus group, Streptococcus constellatus, Streptococcus intermedius, Streptococcus milleri, antimicrobial resistance, MLVA, MLVF, PFGE

\section{Introduction}

Streptococci are a diverse group of Gram positive bacteria divided into multiple clusters based on mixed and constantly changing criteria. Recent classification reflects genetic relationships between groups and separates them into six divisions: (i) pyogenic, (ii) anginosus (formerly milleri), (iii) mitis/oralis, (iv) salivarius, (v) mutans, (vi) bovis and species of unknown evolutionary position such as Streptococcus suis. The genus includes species belonging to physiological flora, human and animal pathogens and opportunistic pathogens (Kohler, 2007). In the past, classification of Streptococci was based mostly on phenotypic traits such as carbohydrate fermentation and later on $16 \mathrm{~S}$ rDNA sequencing. Unfortunately, even with the use of $16 \mathrm{~S}$
rDNA sequencing, some of the strains cannot be clearly classified to previously described streptococcal species (Olson etal., 2013; Thompson et al., 2013). There are some methods available to discriminate streptococcal strains to the species and sub-species level (Poyart et al., 1998; Picard et al., 2004; Glazunova et al., 2010; Zbinden et al., 2011; Obszanska et al., 2015a; Takao et al., 2004). However, sequencing methods are not often used in diagnostic laboratory as the routine species identification and not all microbiology diagnostic laboratories have PCR set up.

Streptococcal groups that include the most pathogenic species are predominantly pyogenic (Streptococcus pyogenes, Streptococcus agalactiae, Streptococcus dysgalactiae subsps. equisimilis and dysgalactiae) and mitis (includes Streptococcus pneumoniae) divisions.

\footnotetext{
* Corresponding author: I. Sitkiewicz, Department of Molecular Microbiology, National Medicines Institute, Warsaw, Poland; e-mail iza.sitkiewicz@gmail.com
} 
However, in recent years, an increasing number of streptococcal species is being considered as pathogenic to humans. Three of the species (Streptococcus anginosus, Streptococcus intermedius and Streptococcus constellatus, SAG - streptococcus anginosus group), described until 1980/1990 as rare sources of infections are currently described as pathogens causing predominantly purulent infections (Asam and Spellerberg, 2014).

The classification of S.anginosus, S. constellatus and S. intermedius is especially confusing as they are described in literature under multiple names. In 1991 Whiley and Beighton proposed a revision of systematic relationships between SAG strains previously described mostly as Streptococcus milleri (Whiley and Beighton, 1991). The proposed classification was recently confirmed by genome analysis using next generation sequencing (Olson etal., 2013) and tandem repeat analysis (Obszanska et al., 2015a).

Unfortunately, SAG are rarely considered as pathogens as they represent the natural flora of the upper respiratory, digestive and reproductive tracts, however, epidemiological data suggest the need to consider SAG an etiological factor of infections ranging from mild skin infections to severe purulent and life threatening infections (Giuliano et al., 2012; Whiley et al., 1992; Asam and Spellerberg, 2014). A correlation between S. intermedius and brain and liver abscesses and S. constellatus and infections of respiratory tract has been detected (Whiley et al., 1992). The majority of published material about SAG is closely related to case reports and suggests that the number of infections caused by SAG is underestimated (Reissmann et al., 2010). Case reports usually describe otherwise healthy patients without any previous medical history and describe the role of SAG in the formation of various kinds of abscesses, which are probably caused by high resistance to phagocytosis and inhibition of chemotaxis (Wanahita et al., 2002). Possible molecular mechanisms involved in that process may include production of hydrogen sulfide from L-cysteine by L-cysteine desulfhydrase (Takahashi et al., 1995). The other postulated possibility draws similarity from increased survival of bacteria upon phagocytosis (Wanahita etal., 2002; Hoe etal., 2002; Voyich et al., 2004).

On the contrary to other streptococcal pathogens, the pathogenicity mechanisms of SAG are often unknown or poorly described (Sitkiewicz and Hryniewicz, 2010; Szczypa et al., 2012; Obszanska et al., 2014). Only recently genomic analyses of SAG genomes were published (Olson et al., 2013; Thompson et al., 2013). Experimental reports describing SAG virulence factors are scarce.

The epidemiological situation in Poland regarding infections with non $\beta$-hemolytic streptococci that are not Streptococcus pneumoniae has been not described so far. Therefore, we decided to investigate strains collected between 1996 and 2012 by reference centers
(KORLD, KOROUN and Polmicro) in Poland and during nationwide viridans streptococci surveillance causing invasive infections (2008-2009).

\section{Experimental}

\section{Materials and Methods}

Bacterial strains. Bacterial strains were collected between 1996 and 2012 by KORLD, KOROUN and Polmicro reference centers during their routine performance and the data about infected patients was stripped from all identifiers, except age, sex and the source of isolation (i.e. blood, wound, puss etc.). Ethics approval was not required. The collected strains were analyzed retrospectively.

Collected strains were stored at $-80^{\circ} \mathrm{C}$ and prior to all microbiological tests or DNA isolation were plated on Columbia agar plates (Becton Dickinson) with 5\% sheep blood and incubated $24-48 \mathrm{~h}$ at $37^{\circ} \mathrm{C}, 5 \% \mathrm{CO}_{2}$. Prolonged incubation was required because of the slow growth of these bacteria.

Strains re-identification. To confirm species identification all strains sent to our reference centers were re-identified using Vitek2 (bioMerieux) automated system with GP card. For the identification we used higher initial inoculum ( $0.5 \mathrm{McF}$ arland) than recommended by the manufacturer. All strains were also identified using IDStrep (bioMerieux) that allows to grow bacteria under optimal $\mathrm{O}_{2} / \mathrm{CO}_{2}$ conditions for time long enough to read the strip and MALDI-TOF MS (Brücker and bioMerieux) according to manufacturer's instructions. All strains were also tested for Lancefield antigen using Strep Plus test (Oxoid).

Antibiotic resistance. Screen for antibiotic resistance was performed using ST101 card (bioMerieux) dedicated to streptococci on Vitek2 system. The card allows detection of ampicillin, benzylpenicillin, cefotaxime, ceftriaxone, clindamycin, erythromycin, levofloxacin, linezolid, tetracycline, trimethoprim/sulfamethoxazole and vancomycin resistance. In some cases only subset of assays from the ST101 card was assayed by the instrument, so to confirm MIC values, for erythromycin, clindamycin, tetracycline, penicillin and linezolid we used E-test (bioMerieux) or M.I.C. Evaluator (Oxoid) or microdilution reference method and applied interpreted according to EUCAST (EUCAST, 2014). For strains with detected resistance to erythromycin, we performed double disc synergy test with erythromycin $(15 \mu \mathrm{g})$ and clindamycin $(2 \mu \mathrm{g})$ according to EUCAST (EUCAST, 2014).

Antibiotic resistance determinants. Chromosomal DNA was isolated as described by Obszanska and coworkers (Obszanska et al., 2015a). Starters and reaction conditions used to detect antibiotic resistance determinants are presented in Table I. 
Table I

Starters and conditions used for detection of antibiotic resistance determinants

\begin{tabular}{|c|c|c|c|c|c|}
\hline Gene & $\begin{array}{c}\text { Starter } \\
\text { name }\end{array}$ & Sequence $\left(5^{\prime}-3^{\prime}\right)$ & Reaction & $\begin{array}{l}\text { Expected } \\
\text { product } \\
\text { size }\end{array}$ & Source \\
\hline erm $\mathrm{A}$ & $\begin{array}{l}\text { ermA_F_IS3 } \\
\text { ermA_R_IS3 }\end{array}$ & $\begin{array}{l}\text { TGGGTCAGGAAAAGGACATTTTACCAAGG } \\
\text { ACATTCGCATGCTTCAGCACCTGT }\end{array}$ & $\begin{array}{l}35 \text { cycles, } \\
\text { Annealing } 67^{\circ} \mathrm{C}, 25 \mathrm{sec} . \\
\text { Elongation } 72^{\circ} \mathrm{C}, 30 \mathrm{sec} .\end{array}$ & $551 \mathrm{bp}$ & This work \\
\hline erm $\mathrm{B}$ & $\begin{array}{l}\text { ermB_F_IS3 } \\
\text { ermB_R_IS2 }\end{array}$ & $\begin{array}{l}\text { CGACGAAACTGGCTAAAATAAGTAAACAGG } \\
\text { ATTGGAACAGGTAAAGGGCATTTAACG }\end{array}$ & $\begin{array}{l}30 \text { cycles, } \\
\text { Annealing } 67^{\circ} \mathrm{C}, 25 \mathrm{sec} . \\
\text { Elongation } 72^{\circ} \mathrm{C}, 30 \mathrm{sec} .\end{array}$ & $600 \mathrm{bp}$ & This work \\
\hline$m e f A$ & $\begin{array}{l}\text { mef_F_IS } \\
\text { mef_R_IS }\end{array}$ & $\begin{array}{l}\text { CGTATTGGGTGCTGTGATTG } \\
\text { AACCCAATTGGCATAGCAAG }\end{array}$ & $\begin{array}{l}30 \text { cycles, } \\
\text { Annealing } 65^{\circ} \mathrm{C}, 25 \mathrm{sec} . \\
\text { Elongation } 72^{\circ} \mathrm{C}, 30 \mathrm{sec} .\end{array}$ & $566 \mathrm{bp}$ & This work \\
\hline tet $\mathrm{O}$ & $\begin{array}{l}\text { TetO_F_IS } \\
\text { TetO_R_IS }\end{array}$ & $\begin{array}{l}\text { CCATCCACATAGAAGTCCCG } \\
\text { GTGGAACATATGCCGAACCT }\end{array}$ & $\begin{array}{l}35 \text { cycles, } \\
\text { Annealing } 57^{\circ} \mathrm{C}, 25 \mathrm{sec} . \\
\text { Elongation } 72^{\circ} \mathrm{C}, 30 \mathrm{sec} .\end{array}$ & $616 \mathrm{bp}$ & This work \\
\hline tet 40 & $\begin{array}{l}\text { Tet } 40 \text { up } \\
\text { Tet } 40 \mathrm{dn}\end{array}$ & $\begin{array}{l}\text { CTACCTGCTGTTCCGATTTGTC } \\
\text { TGATGAAGGTATCACCGCAACC }\end{array}$ & $\begin{array}{l}35 \text { cycles, } \\
\text { Annealing } 67^{\circ} \mathrm{C}, 25 \mathrm{sec} . \\
\text { Elongation } 72^{\circ} \mathrm{C}, 30 \mathrm{sec} .\end{array}$ & & This work \\
\hline tet $\mathrm{M}$ & $\begin{array}{l}\text { tetM-Forward } \\
\text { tetM-Reverse }\end{array}$ & $\begin{array}{l}\text { AGTTTTAGCTCATGTTGATG } \\
\text { TCCGACTATTTGGACGACGG }\end{array}$ & $\begin{array}{l}30 \text { cycles, } \\
\text { Annealing } 55^{\circ} \mathrm{C}, 1 \mathrm{~min} \\
\text { Elongation } 72^{\circ} \mathrm{C}, 1.5 \mathrm{~min}\end{array}$ & $1861 \mathrm{bp}$ & (Doherty et al., 2000) \\
\hline tet $\mathrm{W}$ & $\begin{array}{l}\text { TetW-FW } \\
\text { TetW-RV }\end{array}$ & $\begin{array}{l}\text { GAGAGCCTGCTATATGCCAGC } \\
\text { GGGCGTATCCACAATGTTAAC }\end{array}$ & $\begin{array}{l}25 \text { cycles, } \\
\text { Annealing } 64^{\circ} \mathrm{C}, 30 \mathrm{sec} \\
\text { Elongation } 72^{\circ} \mathrm{C}, 30 \mathrm{sec}\end{array}$ & $168 \mathrm{bp}$ & (Aminov et al., 2001) \\
\hline tetS & $\begin{array}{l}\text { TetS-FWT } 1 \\
\text { TetS-RVT } 2\end{array}$ & $\begin{array}{l}\text { ATCAAGATATTAAGGAC } \\
\text { TTCTCTATGTGGTAATC }\end{array}$ & $\begin{array}{l}30 \text { cycles, } \\
\text { Annealing } 55^{\circ} \mathrm{C}, 1 \mathrm{~min} \\
\text { Elongation } 72^{\circ} \mathrm{C}, 1 \mathrm{~min}\end{array}$ & $573 \mathrm{bp}$ & (Charpentier et al., 1993) \\
\hline tet $\mathrm{T}$ & $\begin{array}{l}\text { TetT-FW } \\
\text { TetT-RV }\end{array}$ & $\begin{array}{l}\text { AAGGTTTATTATATAAAAGTG } \\
\text { AGGTGTATCTATGATATTTAC }\end{array}$ & $\begin{array}{l}25 \text { cycles, } \\
\text { Annealing } 46^{\circ} \mathrm{C}, 30 \mathrm{sec} . \\
\text { Elongation } 72^{\circ} \mathrm{C}, 30 \mathrm{sec} .\end{array}$ & $169 \mathrm{bp}$ & (Aminov et al., 2001) \\
\hline tet $\mathrm{K}$ & $\begin{array}{l}\text { tetK-up } \\
\text { tetK-rev }\end{array}$ & $\begin{array}{l}\text { TATTTTGGCTTTGTATTCTTTCAT } \\
\text { GCTATACCTGTTCCCTCTGATAA }\end{array}$ & \begin{tabular}{|l|}
35 cycles, \\
Annealing $50^{\circ} \mathrm{C}, 1 \mathrm{~min}$ \\
Elongation $72^{\circ} \mathrm{C}, 1.5 \mathrm{~min}$
\end{tabular} & $1159 \mathrm{bp}$ & (Trzcinski et al., 2000) \\
\hline tet $\mathrm{L}$ & $\begin{array}{l}\text { tetL-up } \\
\text { tetL-rev }\end{array}$ & $\begin{array}{l}\text { ATAAATTGTTTCGGGTCGGTAAT } \\
\text { AACCAGCCAACTAATGACAATGAT }\end{array}$ & $\begin{array}{l}35 \text { cycles, } \\
\text { Annealing } 50^{\circ} \mathrm{C}, 1 \mathrm{~min} \\
\text { Elongation } 72^{\circ} \mathrm{C}, 1.5 \mathrm{~min}\end{array}$ & $1077 \mathrm{bp}$ & (Trzcinski et al., 2000) \\
\hline $\operatorname{tet} \mathrm{Q}$ & $\begin{array}{l}\text { MR6 } \\
\text { MR7 }\end{array}$ & $\begin{array}{l}\text { CTGTCCCTAACGGTAAGG } \\
\text { TTATACTTCCTCCGGCATCGG }\end{array}$ & $\begin{array}{l}35 \text { cycles, } \\
\text { Annealing } 46^{\circ} \mathrm{C}, 30 \mathrm{sec} . \\
\text { Elongation } 72^{\circ} \mathrm{C}, 2 \mathrm{~min}\end{array}$ & $658 \mathrm{bp}$ & (Chung et al., 1999) \\
\hline
\end{tabular}

Restriction Fragment Length Polymorphism - Pulsed Field Gel Electrophoresis. RFLP-PFGE analysis and results interpretation were performed as described previously (Obszanska et al., 2015b).

Multi Locus Variable Tandem Repeat Fingerprinting. MLVF analysis and results interpretation were performed as described previously (Obszanska et al., 2015a).

\section{Results and Discussion}

During 16 years of surveillance by reference centers in Poland, we collected only 78 isolates (about 5 isolates a year) confirmed as SAG. Nationwide invasive viridans streptococci strain collection did not significantly increase the number of SAG strains sent to reference centers compared with previous years. It can demonstrate either low level of infections caused by SAG, or poor recognition of SAG as pathogens. It is more likely poor recognition of SAG by health personnel and/or authorities as surveillance reports published worldwide describe much higher incidence reaching 8.65/100,000 population for SAG invasive disease (Laupland et al., 2006; Siegman-Igra et al., 2012; Arinto-Garcia et al., 2015). One of the reports describes a higher incidence of invasive SAG infections than those caused by groups A or B streptococci (Laupland et al., 2006). Unfortunately, in Poland recognition of etiological microbiological factors is rather poor. Epidemiological reports regarding streptococcal infections are usually 
based on the physician's reports and strain collection is not mandatory, reports are then collected by epidemiological authorities and sent to the National Institute of Public Health (NIZP-PZH) and published as bi-weekly reports (NIZP-PZH, 2015). In case of streptococcal infections only $S$. pyogenes infections such as scarlet fever (Lp. 46 in the cited report (NIZP-PZH, 2015)) erysipelas (considered invasive disease, Lp. 55), STSS (Lp. 56), puerperal fever (Lp. 57) and undefined invasive infections (Lp.58) are reported. Using this data, incidence of invasive S. pyogenes is estimated to be $0.03 / 100,000$ population for STSS or $0.2 / 100,000$ population for undefined S.pyogenes invasive infections, what can be an example of dramatically underestimated streptococcal infections. We receive streptococcal strains in reference centers usually in cases when diagnostic laboratories have problems with identifications or there are problems with treatment.

Usually identification of non $\beta$-hemolityc streptococci such as anginosus group is quite a challenge; strains are often misidentified by automated systems because of their slow growth under oxygen conditions. On the other hand manual, and semi-automated system such as ID strips (bioMerieux) often identify species only to anginosus group. To verify systematic classification into species, all strains sent to reference centers as anginosus group, or either Lancefield group $\mathrm{F}$ or non $\beta$-hemolytic Lancefield C and G, were initially re-identified using Vitek2 automated system with GP card (bioMerieux). The results given by IDStrep and MALDI-TOF MS were usually consistent while results from Vitek2 system often misidentified strains as closely related Streptococcus gordonii or called 50\%/50\% identification either as S. anginosus/S. constellatus or S. anginosus/S. intermedius. The problems with identification of streptococci using MALDI-TOF MS have been also reported by other groups (Woods et al., 2014; Chen et al., 2015). So, even with advanced techniques used for strain identification, we experienced multiple problems with proper species identification. In laboratories that routinely perform identification using PCR methods, detection and differentiation of SAG can be performed using molecular methods (Takao et al., 2004). From the clinical point of view, identification to anginosus group is enough to consider an isolate as an etiological factor of infection, however, identification as S. gordonii, which is a natural oral flora, may lead to misdiagnosis and not considering the strain as source of the infection.

Of all strains collected during that time, 48 isolates were consistently identified as S. anginosus, 27 as $S$. constellatus and only one as $S$. intermedius. One isolate could not be identified to the species level using neither IDStrep, VITEK2 nor MALDI-TOF MS system, another isolate was identified as S. anginosus/constellatus. The most common Lancefield antigen detected among SAG isolates was $\mathrm{C}$, followed by $\mathrm{F}$ and $\mathrm{G}$. In case of 20 isolates, we did not detect any of the A, B, C, G and $\mathrm{F}$ Lancefield antigens, what is consistent with group classification (Kohler, 2007). Two isolates of S. constellatus carried antigen A.

Strains from the analyzed collection were isolated from patients of all age groups, from young children to elderly over 65 years. Of all strains with provided information about isolation source, thirteen strains were isolated from invasive infections (blood and cerebrospinal fluid), 23 from pharyngitis and lower respiratory tract infections and 33 from purulent soft tissue infections, including swabs taken during surgeries. Large number of soft tissue isolates is consistent with large number of described purulent infections caused by SAG bacteria (Asam and Spellerberg, 2014). Mean age of patients with blood/CNS infections $v s$ soft tissue $v s$ respiratory tract isolates was different (54 vs 44 vs 35 years of age, respectively), however, only the difference between age of patients with invasive and respiratory tract infections was statistically significant $(\mathrm{p}=0.03)$.

Initial screening for resistance to antibiotics usually used against streptococcal infections was performed using automated Vitek2 system. Unfortunately, similarly to experiences with strain identification, automated minimal inhibitory concentration (MIC) evaluation failed for $\sim 10 \%$ of strains and was performed manually for erythromycin, clindamycin, tetracycline, penicillin and linezolid using E-test (bioMerieux), M.I.C. Evaluator (Oxoid) or reference microdilution method and interpreted according to EUCAST criteria (EUCAST, 2014). In some cases only a subset of assays from the ST101 card was assayed by the instrument.

We did not detect any ampicillin/benzylpenicillin, cefotaxime, ceftriaxone, levofloxacin, linezolid, and vancomycin, resistance and $\mathrm{MIC}_{50}$ and $\mathrm{MIC}_{90}$ values were within "sensitive" range (Fig. 1 and Table II). Unfortunately, clear interpretation criteria for anginosus streptococci cannot be easily applied. In case of some antibiotics such as benzylpenicillin, according to EUCAST (EUCAST, 2014), different breakpoints should be applied for $\beta$-hemolytic streptococci (such as $S$. pyogenes), different to $S$. pneumoniae and different to a large group of species named viridans streptococci (Fig. 1 and Table II). Based on the slowly increasing knowledge about anginosus streptococci, it is not clear which group of breakpoints should be applied for the analysis.

Among the analyzed strains, several of them were resistant to erythromycin and/or clindamycin, however $\mathrm{MIC}_{50}$ and $\mathrm{MIC}_{90}$ values for the population were still within "sensitive" range. In case of detected erythromycin resistance, double disc diffusion test was performed to determine inducible or constitutive mechanism of the resistance. Among 5 strains with detected ermA gene, 3 strains exhibited inducible clindamycin resistance. 


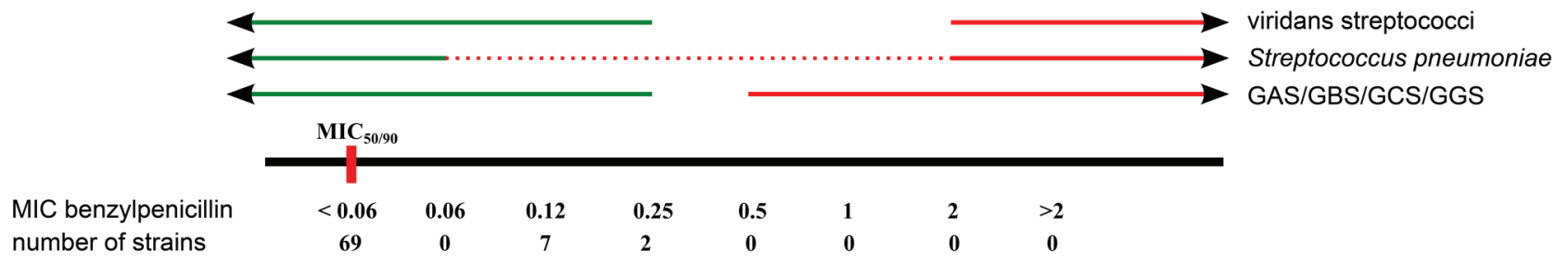

MIC erythromycin number of strains

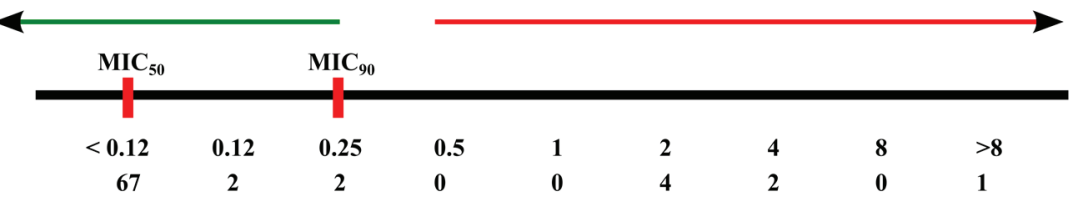

MIC clindamycin number of strains
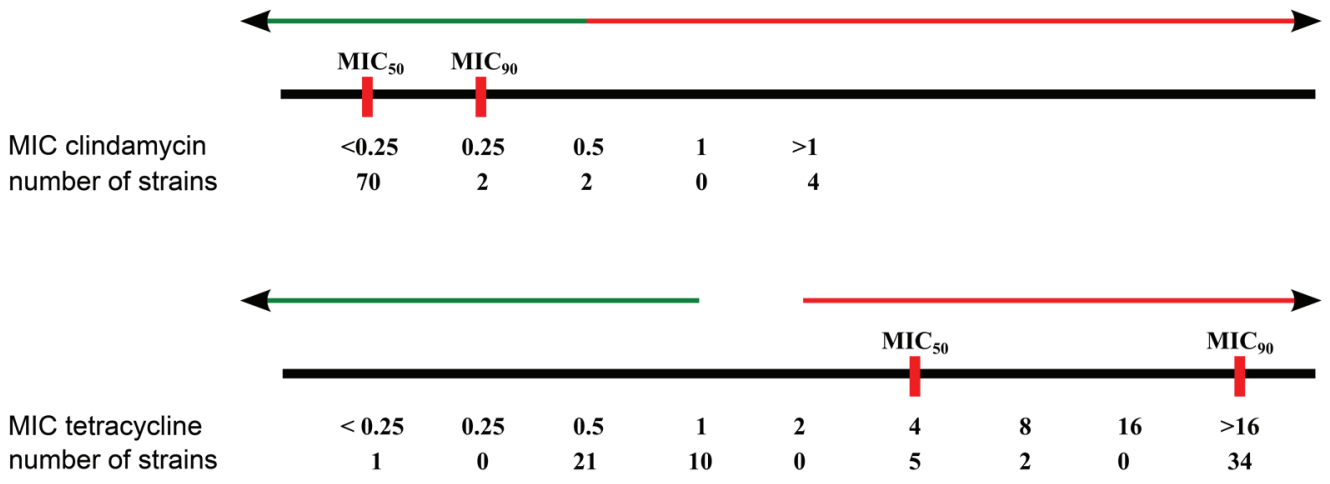

Fig. 1. MIC values detected for benzylpenicillin, erythromycin, clindamycin and tetracycline. Horizontal green and red arrows denote sensitive/resistant breakpoints according to EUCAST (EUCAST, 2014). In case of benzylpenicillin, breakpoints for GAS/GBS/GCS/GGS, S. pneumoniae and viridans streptococci are shown. Red rectangles on the horizontal axis denote MIC50 or MIC90. For each antibiotic dilution number of strains with detected MIC is given.

Contrary to detected sensitivity to the majority of tested antibiotics, over $50 \%$ of strains were resistant to tetracycline, with $\mathrm{MIC}_{50}$ and $\mathrm{MIC}_{90}$ values within "resistant" range according to Eucast (Fig. 1).
To identify genes responsible for the resistance phenotypes, we performed PCR detection of resistance determinants using chromosomal DNA isolated from all analyzed strains with starters that allow detection of

Table II

$\mathrm{MIC}_{50}$ and $\mathrm{MIC}_{90}$ values estimated for group of analyzed SAG strains.

\begin{tabular}{|l|c|c|c|c|}
\hline \multicolumn{1}{|c|}{ Antibiotic } & $\mathrm{MIC}_{50}$ & $\mathrm{MIC}_{90}$ & Breakpoints for sensitive S & Breakpoints for resistant R $>$ \\
\hline Ampicillin & $<0.25$ & $<0.25$ & $\mathrm{ND} / 0.5 / 0.5$ & $\mathrm{ND} / 2 / 2$ \\
\hline Benzylpenicillin & $<0.06$ & $<0.06$ & $0.25 / 0.06 / 0.25$ & $0.25 / 2 / 2$ \\
\hline Cefotaxime & $<0.12$ & 0.25 & $\mathrm{ND} / 0.5 / 0.5$ & $\mathrm{ND} / 2 / 0.5$ \\
\hline Ceftriaxone & 0.25 & 0.5 & $\mathrm{ND} / 0.5 / 0.5$ & $0.5 / 0.5 / 0.5$ \\
\hline Clindamycin & $<0.25$ & 0.25 & $0.5 / 0.5 / 0.5$ & $0.5 / 0.5 /-$ \\
\hline Erythromycin & $<0.12$ & 0.25 & $0.25 / 0.25 /-$ & $2 / 2 /-$ \\
\hline Levofloxacin & 0.5 & 1 & $1 / 2 /-$ & $4 / 4 /-$ \\
\hline Linezolid & $<2$ & $<2$ & $2 / 2 /-$ & $2 / 2 /-$ \\
\hline Tetracycline & 4 & $>16$ & $1 / 1 /-$ & $2 / 2 /-^{\star}$ \\
\hline Trimethoprim /sulfamethoxazole & $<10(0.5 / 9.5)$ & $40(2 / 38)$ & $1 / 1 /-^{\star}$ & $2 / 2 / 2$ \\
\hline Vancomycin & 0.5 & 0.75 & $2 / 2 / 2$ & \\
\hline
\end{tabular}

MIC values for sensitive (S) or resistant (R) classes are given for $\beta$-hemolytic streptococci / S. pneumoniae / viridans streptococci, respectively, according to EUCAST, “-” insufficient data supporting S vs R call or antibiotic not recommended for use, ND not determined and sensitivity for $\beta$-hemolytic streptococci inferred from sensitivity to benzylpenicillin. ${ }^{\star}$ EUCAST breakpoints for trimethoprim/sulfamethoxazole are expressed as trimethoprim concentration. trimethoprim/sulfamethoxazole tested with ST-101 card in the ratio 1:19. 


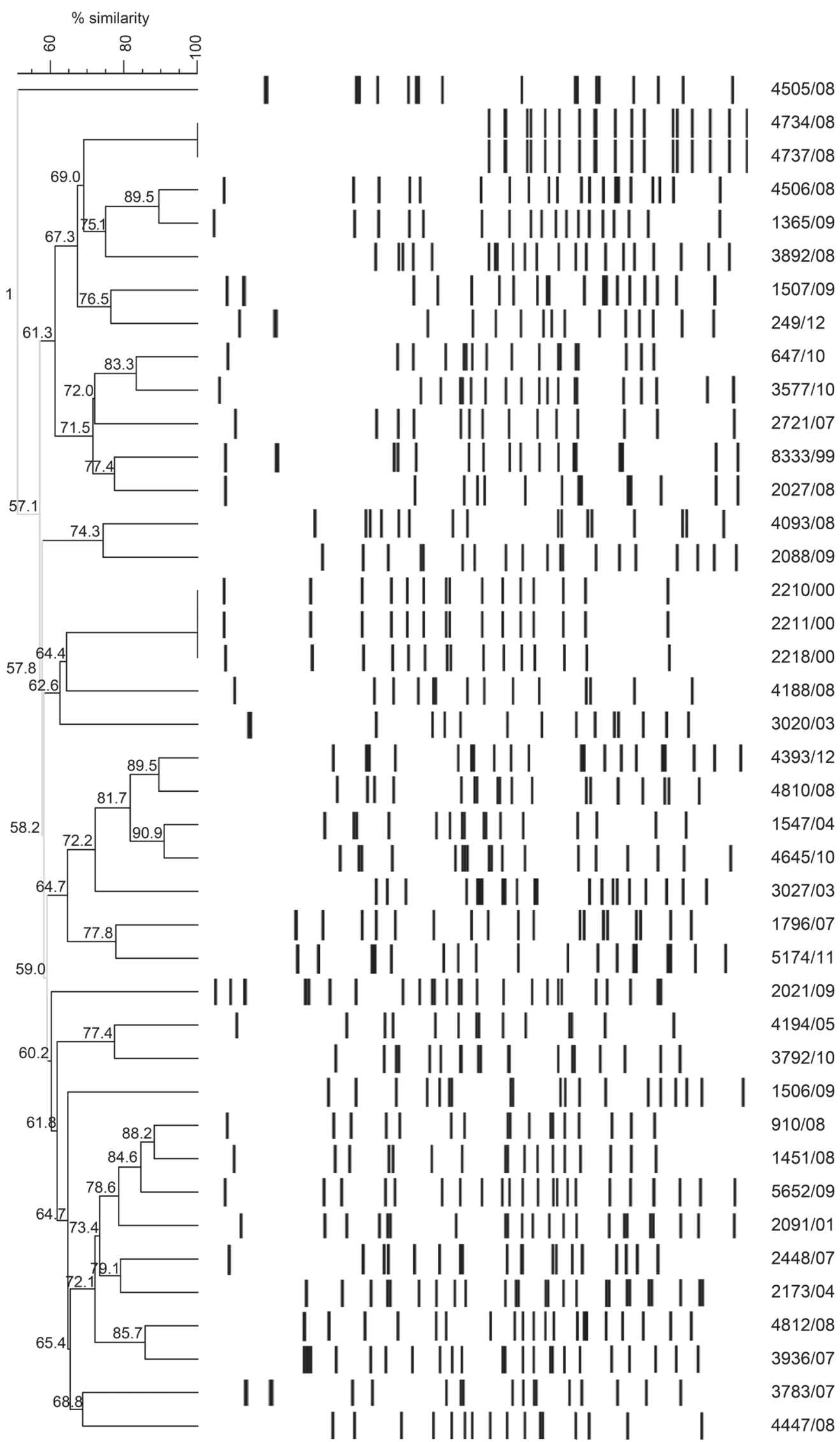

Fig. 2. RFLP-PFGE analysis of SAG strains resistant to tetracycline or macrolide antibiotics. Analysis was performed as described in (Obszanska et al., 2015b), and DNA in plugs was digested with EagI. The similarity coefficient was calculated using Dice algorithm (optimization and tolerance parameters set to 1\%), followed by clustering analysis using UPGMA method (BioNumerics). Numbers on the dendrogram show percent of similarity between branches. 


\section{A}

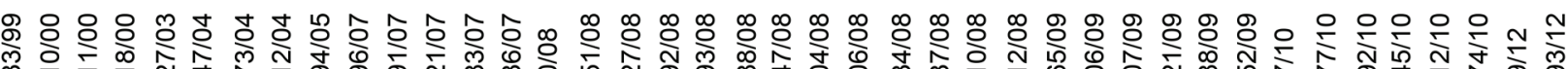

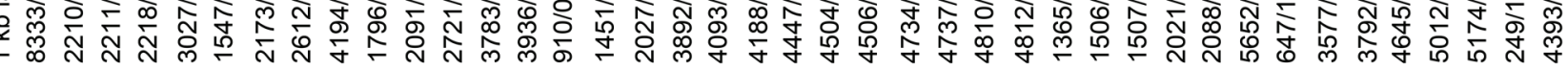

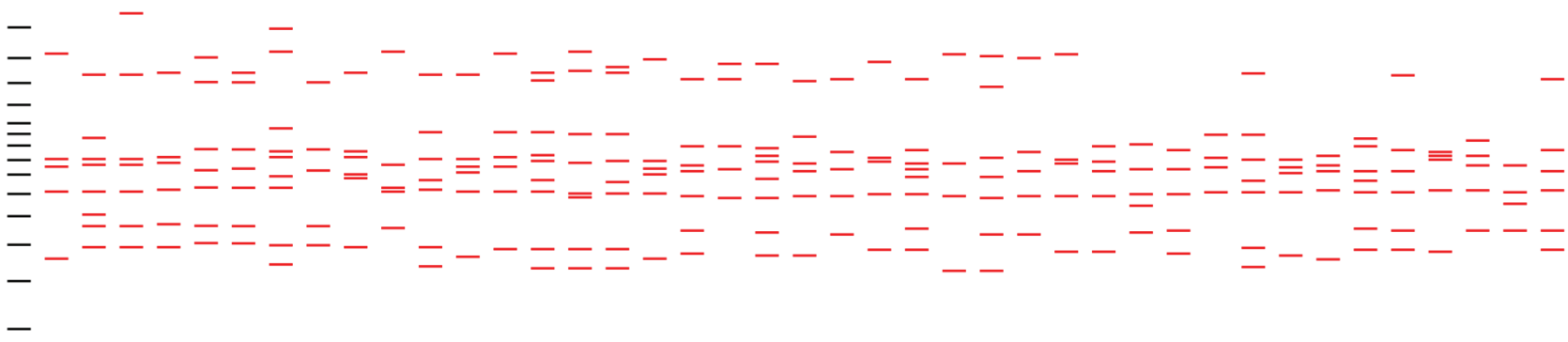

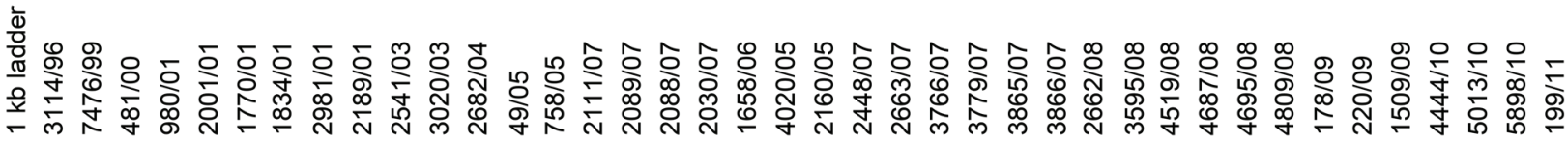

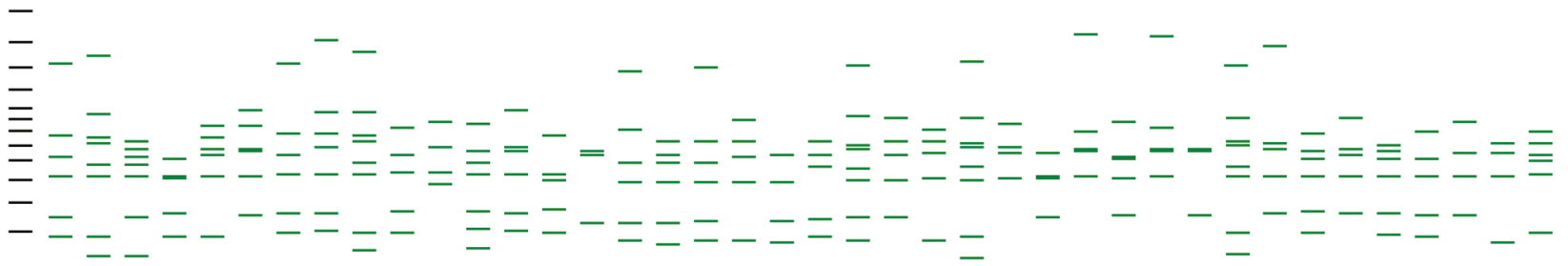

B

$4695 / 08$

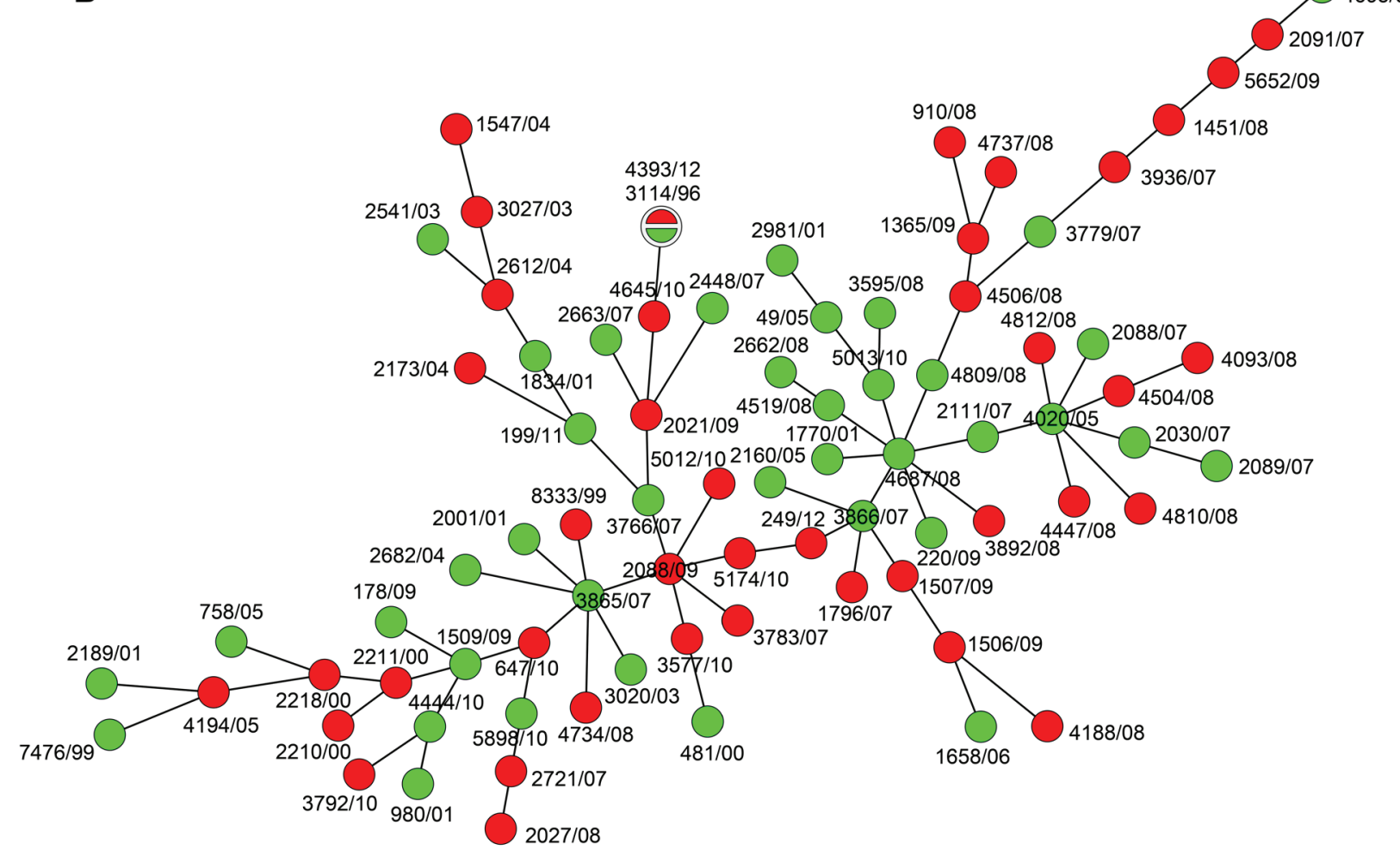

Fig. 3. MLVF analysis of SAG collection.

A. Unclustered patterns obtained using MLVF typing (Obszanska et al., 2015a), patterns in red represent strains resistant to tetracycline, erythromycin and clindamycin, patterns in green represent strains sensitive to all tested antibiotics.

B. Minimum spanning tree generated using MLVF patterns, similarity coefficient was calculated based on the number of different bands with optimization and tolerance set to $0.3 \%$. Red circles represent strains resistant to tetracycline, erythromycin and clindamycin, green circles represent strains sensitive to all tested antibiotics 
Table III

Antibiotic resistance determinants detected for analyzed population

\begin{tabular}{|c|c|c|c|}
\hline \multirow{2}{*}{ Antibiotic } & $\begin{array}{c}\text { Number of } \\
\text { resistant strains }\end{array}$ & $\begin{array}{c}\text { Number } \\
\text { of strains }\end{array}$ & $\begin{array}{c}\text { Resistance } \\
\text { determinant }\end{array}$ \\
\hline Tetracycline & $40 / 78(51 \%)$ & 30 & tet $\mathrm{M}$ \\
\cline { 2 - 4 } & & 1 & tet $\mathrm{O}$ \\
\cline { 2 - 4 } & & 1 & tet $\mathrm{W}$ \\
\cline { 2 - 4 } & & 8 & Not found \\
\hline Erythromycin & $7 / 78(9 \%)$ & 4 & erm $\mathrm{A}$ \\
\cline { 2 - 4 } & & 1 & erm $\mathrm{B}$ \\
\cline { 2 - 4 } & & 1 & mef $\mathrm{A}$ \\
\cline { 2 - 4 } & & 1 & mefA + erm $\mathrm{A}$ \\
\hline
\end{tabular}

erythromycin and tetracycline determinants in streptococci (Table III). For all strains resistant to erythromycin, we were able to detect the gene responsible for the phenotype, however in case of tetracycline resistance we could not detect any resistance determinant in 8 strains with any of the starters listed above. This suggests the presence of a novel variant of the resistance gene/genes that cannot be amplified with the used starters.

To test whether resistant strains are similar to each other, we performed strain comparison on the genomic level using modified PFGE (Fig. 2). The analysis shows that the group of resistant strains is highly diverse, except for two small clusters that exhibit the same patterns. Strains 2210/00, 2211/00 and 2218/00 were sent to the reference center from the same hospital to confirm species identification. Unfortunately, we do not have any additional epidemiological records, nor access to them. The strains may be as well isolates from multiple patients or sequential isolates from the same person. Based on the PFGE pattern they can be considered almost identical. Two other strains (4737/08 and 4734/08) were sent to the reference center during the survey from the same hospital, but were isolated from two different patients and different infections (blood and lower respiratory tract, respectively).

To further investigate the relationships between strains, we performed multi locus analysis of variable number of tandem repeats (MLVF) (Fig. 3). The analysis was performed for strains that belonged to both "sensitive" and "resistant" groups to see whether the "resistant" group shows any unique traits in comparison with the "sensitive" group. The analysis showed very similar patterns detected for 3 strains 2210/00, 2211/00 and 2218/00, confirming the common source. However, strains 4737/08 and 4734/08 with identical PFGE pattern, shown different MLVF profiles, consistent with two different sources. We did not observe any significant clustering of MLVF patterns for resistant or sensitive strains (Fig. 3) and MLVF analysis confirms that all SAG strains isolated in Poland are diverse on the genetic level.
Conclusions. Streptococci belonging to anginosus group are rarely isolated in Poland presumably because of poor recognition by epidemiological and health authorities, predominantly from purulent infections. All analyzed isolates are very diverse on the genomic level as estimated by PFGE and MLVF analyses. All analyzed strains are sensitive to penicillin, a substantial group of strains is resistant to macrolides and the majority of strains are resistant to tetracycline.

\section{Abbreviations}

CNS - central nervous system; EUCAST - The European Committee on Antimicrobial Susceptibility Testing; KORLD - Krajowy Ośrodek Referencyjny d.s. Lekowrażliwości Drobnoustrojów (National Reference Center for Antimicrobial Resistance); KOROUN - Krajowy Ośrodek Referencyjny d.s. Zakażeń Ośrodkowego Układu Nerwowego (National Reference Center for Central Nervous System Infections); MALDI-TOF MS - MatrixAssisted Laser Desorption/Ionization-Time of Flight Mass Spectrometer; MIC - Minimal Inhibitory Concentration, MLVF - Multi Locus Variable tandem repeats Fingerprinting; RFLP-PFGE, Restriction Fragment Length Polymorphism - Pulsed Field Gel Electrophoresis; SAG - Streptococcus anginosus group

\section{Competing interests}

The authors have no competing interests to declare

\section{Authors contribution}

KO performed strain re-identification, MLVF and PFGE analyses and wrote the manuscript, IKZ performed PFGE analysis, AK performed MIC analysis, KM performed MIC analysis and detection of antibiotic resistance determinants, ES coordinated strain collection, performed strain re-identification, WH analyzed the data, IS coordinated the study, analyzed the data and wrote the manuscript

\section{Acknowledgments}

The study was financed from grant N401535940 from NCN (National Science Center), partially supported from NIL internal funding (DS 5.02), SPUB-Mikrobank2 and the National Programme of Antibiotic Protection (MODUL I NPOA).

We are thankful to members of KORLD, KOROUN and Polmicro for help with strain banking and maintenance.

\section{Literature}

Aminov R.I., N. Garrigues-Jeanjean and R.I. Mackie. 2001. Molecular ecology of tetracycline resistance: development and validation of primers for detection of tetracycline resistance genes encoding ribosomal protection proteins. Appl. Environ. Microbiol. 67: 22-32. Arinto-Garcia R., M.D. Pinho, J. Carrico, J. Melo-Cristino and M. Ramirez. 2015. Comparing MALDI-TOF MS, phenotypic and molecular methods for the identification of species within the Streptococcus anginosus group. J. Clin. Microbiol. 53(11): 3580-3588.

Asam D. and B. Spellerberg. 2014. Molecular pathogenicity of Streptococcus anginosus. Mol. Oral Microbiol. 29: 145-155.

Charpentier E., G. Gerbaud and P. Courvalin. 1993. Characterization of a new class of tetracycline-resistance gene tet(S) in Listeria monocytogenes BM4210. Gene 131: 27-34.

Chen J.H., K.K. She, O.Y. Wong, J.L. Teng, W.C. Yam, S.K. Lau, P.C. Woo, V.C. Cheng and K.Y. Yuen. 2015. Use of MALDI Biotyper 
plus ClinProTools mass spectra analysis for correct identification of Streptococcus pneumoniae and Streptococcus mitis/oralis. J. Clin. Pathol. 68(8): 652-656.

Chung W.O., K. Young, Z. Leng and M.C. Roberts. 1999. Mobile elements carrying erm $\mathrm{F}$ and tet $\mathrm{Q}$ genes in gram-positive and gramnegative bacteria. J. Antimicrob. Chemother. 44: 329-335.

Doherty N., K. Trzcinski, P. Pickerill, P. Zawadzki and C.G. Dowson. 2000. Genetic diversity of the tet(M) gene in tetracycline-resistant clonal lineages of Streptococcus pneumoniae. Antimicrob. Agents Chemother. 44: 2979-2984.

EUCAST. 2014. Breakpoint table for bacteria. http://www.eucast. org/clinical_breakpoints/, 2015.12.01.

Giuliano S., G. Rubini, A. Conte, P. Goldoni, M. Falcone, A. Vena, M. Venditti and S. Morelli. 2012. Streptococcus anginosus group disseminated infection: case report and review of literature. Infez. Med. 20: 145-154.

Glazunova O.O., D. Raoult and V. Roux. 2010. Partial recN gene sequencing: a new tool for identification and phylogeny within the genus Streptococcus. Int. J. Syst. Evol. Microbiol. 60: 2140-2148.

Hoe N.P., R.M. Ireland, F.R. DeLeo, B.B. Gowen, D.W. Dorward, J.M. Voyich, M. Liu, E.H. Burns Jr., D.M. Culnan, A. Bretscher and others. 2002. Insight into the molecular basis of pathogen abundance: group A Streptococcus inhibitor of complement inhibits bacterial adherence and internalization into human cells. Proc. Natl. Acad. Sci. USA 99: 7646-7651.

Kohler W. 2007. The present state of species within the genera Streptococcus and Enterococcus. Int. J. Med. Microbiol. 297: 133-150.

Laupland K.B., T. Ross, D.L. Church and D.B. Gregson. 2006. Population-based surveillance of invasive pyogenic streptococcal infection in a large Canadian region. Clin. Microbiol. Infect. 12: 224-230.

Obszanska K., I. Kern-Zdanowicz and I. Sitkiewicz. 2014. Virulence mechanisms factors and pathogenic of $\beta$-hemolytic streptococci (in Polish). Post. Mikrobiol. 53: 101-111.

Obszanska K., I. Kern-Zdanowicz and I. Sitkiewicz. 2015a. MLVF analysis of anginosus (milleri) group streptococci. Diagn. Microbiol. Infect. Dis. 83(2): 124-129.

Obszanska K., I. Kern-Zdanowicz and I. Sitkiewicz. 2015b. Optimized Protocol for PFGE Analysis of Anginosus (milleri) Streptococci. Pol. J. Microbiol. 64: 61-64.

Olson A.B., H. Kent, C.D. Sibley, M.E. Grinwis, P. Mabon, C. Ouellette, S. Tyson, M. Graham, S.D. Tyler, G. Van Domselaar and others. 2013. Phylogenetic relationship and virulence inference of Streptococcus anginosus group: curated annotation and wholegenome comparative analysis support distinct species designation. BMC Genomics 14: 895.

Picard F.J., D. Ke, D.K. Boudreau, M. Boissinot, A. Huletsky, D. Richard, M. Ouellette, P.H. Roy and M.G. Bergeron. 2004. Use of tuf sequences for genus-specific PCR detection and phylogenetic analysis of 28 streptococcal species. J. Clin. Microbiol. 42: 3686-3695.

Poyart C., G. Quesne, S. Coulon, P. Berche and P. Trieu-Cuot. 1998. Identification of streptococci to species level by sequencing the gene encoding the manganese-dependent superoxide dismutase. J. Clin. Microbiol. 36: 41-47.

Reissmann S., C. Friedrichs, R. Rajkumari, A. Itzek, M. Fulde, A.C. Rodloff, K.N. Brahmadathan, G.S. Chhatwal and D.P. Nitsche-Schmitz. 2010. Contribution of Streptococcus anginosus to infections caused by groups $\mathrm{C}$ and $\mathrm{G}$ streptococci, southern India. Emerg. Infect. Dis. 16: 656-663.

Siegman-Igra Y., Y. Azmon and D. Schwartz. 2012. Milleri group streptococcus-a stepchild in the viridans family. Eur. J. Clin. Microbiol. Infect. Dis. 31: 2453-2459.

Sitkiewicz I. and W. Hryniewicz. 2010. Pyogenic streptococcidanger of re-emerging pathogens. Pol. J. Microbiol. 59: 219-226.

Szczypa K., J. Wilemska, W. Hryniewicz and I. Sitkiewicz. 2012. Patogenicity mechanisms of Streptococcus pyogenes (in Polish). Post. Mikrobiol. 51: 3-15.

Takahashi S., Y. Nagano, N. Nagano, O. Hayashi, F. Taguchi and Y. Okuwaki. 1995. Role of C5a-ase in group B streptococcal resistance to opsonophagocytic killing. Infect. Immun. 63: 4764-4769. Takao A., H. Nagamune and N. Maeda. 2004. Identification of the anginosus group within the genus Streptococcus using polymerase chain reaction. FEMS Microbiol. Lett. 233: 83-89.

Thompson C.C., V.E. Emmel, E.L. Fonseca, M.A. Marin and A.C. Vicente. 2013. Streptococcal taxonomy based on genome sequence analyses. F1000Res. 2: 67.

Trzcinski K., B.S. Cooper, W. Hryniewicz and C.G. Dowson. 2000. Expression of resistance to tetracyclines in strains of methicillin-resistant Staphylococcus aureus. J. Antimicrob. Chemother. 45: 763-770.

Voyich J.M., K.R. Braughton, D.E. Sturdevant, C. Vuong, S.D. Kobayashi, S.F. Porcella, M. Otto, J.M. Musser and F.R. DeLeo. 2004. Engagement of the pathogen survival response used by group A Streptococcus to avert destruction by innate host defense. J. Immunol. 173: 1194-1201.

Wanahita A., E.A. Goldsmith, D.M. Musher, J.E. Clarridge, 3rd, J. Rubio, B. Krishnan and J. Trial. 2002. Interaction between human polymorphonuclear leukocytes and Streptococcus milleri group bacteria. J. Infect. Dis. 185: 85-90.

Whiley R.A. and D. Beighton. 1991. Emended descriptions and recognition of Streptococcus constellatus, Streptococcus intermedius, and Streptococcus anginosus as distinct species. Int. J. Syst. Bacteriol. 41: 1-5.

Whiley R.A., D. Beighton, T.G. Winstanley, H.Y. Fraser and J.M. Hardie. 1992. Streptococcus intermedius, Streptococcus constellatus, and Streptococcus anginosus (the Streptococcus milleri group): association with different body sites and clinical infections. J. Clin. Microbiol. 30: 243-244.

Woods K., D. Beighton and J.L. Klein. 2014. Identification of the 'Streptococcus anginosus group' by matrix-assisted laser desorption ionization--time-of-flight mass spectrometry. J. Med. Microbiol. 63: 1143-1147.

Zbinden A., N. Kohler and G.V. Bloemberg. 2011. recA-based PCR assay for accurate differentiation of Streptococcus pneumoniae from other viridans streptococci. J. Clin. Microbiol. 49: 523-527. 
